\title{
Prevention and Management of Gastroesophageal Varices in Cirrhosis
}

\author{
Yen-I Chen ${ }^{1,2}$ and Peter Ghali ${ }^{1}$ \\ ${ }^{1}$ Division of Hepatology and Gastroenterology, McGill University Health Center, McGill University, Montreal, QC, Canada H3A 1A1 \\ ${ }^{2}$ Internal Medicine Office, Jewish General Hospital, Montreal, QC, Canada H3T $1 E 2$
}

Correspondence should be addressed to Yen-I Chen, cyen33@gmail.com

Received 24 January 2012; Accepted 5 March 2012

Academic Editor: Averell Sherker

Copyright ( $) 2012$ Y.-I. Chen and P. Ghali. This is an open access article distributed under the Creative Commons Attribution License, which permits unrestricted use, distribution, and reproduction in any medium, provided the original work is properly cited.

\begin{abstract}
Variceal hemorrhage is one of the major complications of liver cirrhosis associated with significant mortality and morbidity. Its management has evolved over the past decade and has substantially reduced the rate of first and recurrent bleeding while decreasing mortality. In general, treatment of esophageal varices can be divided into three categories: primary prophylaxis (prevention of first episode of bleeding), management of acute bleeding, and secondary prophylaxis (prevention of recurrent hemorrhage). The goal of this paper is to describe the current evidence behind the management of esophageal varices. We will discuss indications for primary prophylaxis and the different modes of therapy, pharmacological and interventional treatment in acute bleeding, and therapeutic options in preventing recurrent bleeding. The indications for TIPS will also be reviewed including its possible benefits in acute variceal hemorrhage.
\end{abstract}

\section{Introduction}

Portal hypertension in liver cirrhosis results from the anatomical changes and the development of contractile element in the liver vascular bed secondary to progressive hepatic fibrosis and formation of regenerative nodules $[1,2]$. The increase in portal pressure triggers splanchnic vasodilation, increased cardiac output, and fluid/salt retention leading to a hyperdynamic circulation and increased portal flow. Formation of collaterals between the portal and systemic systems such as those found in the lower esophagus and gastric cardia (gastroesophageal varices) may not only relieve some of the pressure, but also pose a risk for rupture and bleeding [2].

The prevalence of gastroesophageal varices ranges from $0-40 \%$ in compensated cirrhosis to $70-80 \%$ in decompensated liver disease, while their growth and progression occur at an estimated $7 \%$ per year $[2,3]$. The one-year rate of first variceal hemorrhage is $5 \%$ for small varices and $15 \%$ for large varices [4]. Advanced liver disease (Child B or C), large varices, and varices with red wale marks are bad prognostic signs associated with higher incidence of bleeding. Six-week mortality with each episode of bleeding varies between 15 and $20 \%$ and is largely dependent on the severity of the liver disease ( $0 \%$ for Child A and 30\% for Child C) [5-7]. Finally, the 1-year rebleeding rate following initial variceal hemorrhage is approximately $60 \%$ [8].

The current treatment of gastroesophageal varices has substantially reduced the rate of first and recurrent bleeding while decreasing the mortality of acute variceal hemorrhage $[9,10]$. The purpose of this paper is to summarize the management of gastroesophageal varices in terms of primary prophylaxis (prevention of first episode of bleeding), treatment of acute hemorrhage, and secondary prophylaxis (prevention of recurrent bleeding).

\section{Primary Prophylaxis}

Nonselective beta-blockers are the current mainstay of therapy in the prevention of first episode variceal hemorrhage [911]. $\beta 1$ inhibition reduces cardiac output while $\beta 2$-blockade induces splanchnic vasoconstriction and together it results in decreased portal flow and pressure [12]. Nonselective betablockers used for primary prophylaxis in North America include propranolol and nadolol. Carvedilol has recently 
been investigated in portal hypertension given its alphablocking component and its potential to better diminish portal pressure [13]. However, more data will be needed on its effectiveness and long-term safety. At this time it is premature to endorse Carvedilol as a first-line agent for primary prophylaxis. In terms of dosing and goal of treatment, it is recommended to start at a low dose and to titrate up as tolerated until a heart rate of 55 beats/minute is achieved [9-11].

2.1. Cirrhosis with Small Varices. In patients with low-risk small varices (Child A without red wale marks), the use of nonselective beta-blocker is optional [9]. There is limited evidence showing that nonselective beta-blockers may slow the growth of varices but they do not reduce mortality and their use cannot be universally recommended over regular endoscopic surveillance (every 2 years and annually with hepatic decompensation) [14]. However, nonselective betablockers are recommended in patients with small varices and high-risk features such as red wale marks and/or Child B-C cirrhosis [9].

2.2. Cirrhosis with Medium to Large Varices. A large metaanalysis looking at propranolol/nadolol versus placebo, in patients with cirrhosis and medium to large varices, found a significantly lower incidence of first variceal bleeding in the treatment group: $14 \%$ compared to $30 \%$ [4]. Also, these nonselective beta-blockers may be equivalent to endoscopic variceal band ligation (EVBL) in terms of primary prevention and mortality rate $[15,16]$. In addition, they are inexpensive and can potentially prevent other complications of cirrhosis such as spontaneous bacterial peritonitis and bleeding from portal hypertensive gastropathy $[17,18]$. However, 15$20 \%$ of patients treated with nonselective beta-blockers are noncompliant due to common side effects such as fatigue, dizziness, and shortness of breath. EVBL is associated with fewer side effects and does not rely on patient compliance but requires technical expertise and can lead to serious complications such as bleeding from ligation-induced ulcers $[12,19]$. Finally, a randomized controlled trial comparing EVBL and propranolol to EVBL alone in patients with large varices did not show a difference in terms of mortality or incidence of first bleed [20]. Therefore, depending on patient/physician preference and available expertise either nonselective beta-blocker or EVBL alone should be used for primary prophylaxis in cirrhosis with medium to large varices. Combination therapy does not seem to confer any additional benefit (Table 1).

\section{Acute Variceal Bleeding}

The management of acute variceal bleeding with the combination of vasoconstrictors, endoscopic therapy, and antibiotics has decreased mortality substantially $[9,10]$. Initial assessment of a patient with acute variceal hemorrhage begins with the evaluation of airway, breathing, and circulation. Many of these patients are at risk for aspiration and intubation is often performed for airway protection, although there are limited data to justify this practice $[21,22]$. Volume resuscitation with blood and fluid is essential in the initial stabilization; however, experimental studies suggest that overly aggressive volume repletion can worsen bleeding and increase the rate of rebleeding and mortality [23]. Therefore, meticulous resuscitation with a target hemoglobin level of $8 \mathrm{~g} / \mathrm{dL}$ is recommended $[23,24]$. In addition, animal studies suggest that blood transfusion may be superior to fluid administration given that fluid resuscitation may decrease blood viscosity, which can exacerbate portal pressure and potentially worsen acute variceal hemorrhage [25]. Correction of significant coagulopathy and thrombocytopenia with fresh frozen plasma and platelet transfusions should also be considered [10]. Studies on Factor VIIa have failed to show benefit in terms of mortality and control of bleeding and its use is currently not recommended [6].

\section{Antibiotics in Acute Variceal Bleeding}

Acute variceal hemorrhage has been shown to increase the risk for severe bacteremia, which is associated with higher mortality rates and greater incidence of rebleeding [2628]. Meta-analyses have revealed that antibiotic prophylaxis can improve short-term survival while decreasing bacterial infections and rebleeding rates $[26,29,30]$. Oral norfloxacin or intravenous ciprofloxacin for 7-days, administered at the time of acute bleeding, works by decreasing the amount of gram-negative bacteria in the gut believed to be the most common source for infection in cirrhosis $[27,28]$. However, in patients with advanced cirrhosis (Child $\mathrm{B} / \mathrm{C}$ ) ceftriaxone may be superior to norfloxacin in preventing infections [28]. This is likely due to ceftriaxone's extended coverage against nonenterococcal streptococci and quinolone-resistant Gram-negative bacteria. Therefore, cirrhotic patients without advanced liver insufficiency and acute variceal hemorrhage should receive either oral norfloxacin or IV ciprofloxacin for 7 days while ceftriaxone is preferred in patients with Child $\mathrm{B} / \mathrm{C}$ cirrhosis or previous quinolone use.

\section{Pharmacological Therapy and Endoscopic Management}

In addition to antibiotics, vasoactive agents such as vasopressin, terlipressin, somatostatin, and octreotide play a major role in controlling acute esophageal variceal hemorrhage through their ability to induce splanchnic vasoconstriction thereby reducing portal flow and pressure $[9,10]$. In fact, they may be equally as effective as endoscopic sclerotherapy in controlling initial bleeding and in preventing rebleeding with less adverse effects $[31,32]$. These agents, when administered at the time when variceal bleeding is suspected, can achieve initial hemostasis in $60-80 \%$ of the cases [33].

Vasopressin is a potent vasoconstrictor that reduces blood flow to all splanchnic organs leading to substantial decreases in portal pressure [10]. However, its use has been limited by its side effects such as hypertension, cardiac, and peripheral ischemia, and ischemic bowel. Terlipressin is a synthetic analogue of vasopressin with longer pharmacological activity and fewer side effects $[4,10,34]$. The intact 
TABLE 1: Primary prophylaxis and surveillance.

\begin{tabular}{|c|c|c|c|}
\hline $\begin{array}{l}\text { Surveillance/prophylaxis } \\
\text { modalities }\end{array}$ & Indications & Dose & Goal \\
\hline Endoscopic surveillance & $\begin{array}{l}\text { Low-risk* small varices } \\
\text { (not on nonselective } \mathrm{BB}^{* *} \text { ) }\end{array}$ & $\begin{array}{l}\text { Every } 2 \text { years and } \\
\text { annually with liver } \\
\text { decompensation }\end{array}$ & $\begin{array}{l}\text { Surveillance for progression into } \\
\text { higher-risk lesions needing medical or } \\
\text { endoscopic prophylaxis }\end{array}$ \\
\hline Nadolol & $\begin{array}{l}\text { High-risk }{ }^{* * *} \text { small varices and } \\
\text { medium-large varices } \\
\text { Optional: low-risk small varices }\end{array}$ & Start: $40 \mathrm{mg}$ qd & $\begin{array}{l}\text { Titrate to heart rate: } 55 \text { beats/minute } \\
\text { or maximally tolerated dose }\end{array}$ \\
\hline Propranolol & $\begin{array}{l}\text { High-risk small varices and } \\
\text { medium-large varices } \\
\text { Optional: low-risk small varices }\end{array}$ & Start: $10 \mathrm{mg}$ bid & $\begin{array}{l}\text { Titrate to heart rate: } 55 \text { beats/minute } \\
\text { or maximally tolerated dose }\end{array}$ \\
\hline EVBL & Medium to large varices & Every 2-4 weeks & Until variceal obliteration \\
\hline
\end{tabular}

${ }^{*}$ Low-risk: Child A cirrhosis and no red wale marks, ${ }^{* *}$ beta-blocker, ${ }^{* * *}$ high-risk: Child B or C cirrhosis and/or presence of red wale marks.

molecule has immediate vasoconstrictive activity, which is followed by a delayed effect secondary to a slow enzymatic breakdown of terlipressin into vasopressin. It is the only agent that has been demonstrated to decrease mortality in acute variceal hemorrhage [4]; however, it is not yet available in North America. In terms of dosing, terlipressin is given intravenously and should be started at $2 \mathrm{mg}$ every 4 hours for 48 hours, followed by $1 \mathrm{mg}$ every 4 hours [9]. The optimal duration of treatment is unknown but current recommendations suggest a total of $2-5$ days.

Somatostatin is a naturally occurring tetradecapeptide that has inhibitory effects on exocrine/endocrine hormones, gastrointestinal motility, and systemic blood flow leading to a decreased circulation and pressure in the portal and portocollateral system [34]. Octreotide, a synthetic analogue of somatostatin with greater potency and longer half-life, is the only substance available in North America mainly due to its safety profile and its apparent effectiveness when used in combination with EVBL $[9,34,35]$. However, its effectiveness in controlling acute variceal hemorrhage has not been firmly established $[11,34]$. In terms of dosing, it is administered intravenously and should be initiated with a $50 \mathrm{mcg}$ bolus followed by an infusion at $50 \mathrm{mcg} / \mathrm{hr}$ [9]. A bolus can be repeated in the first hour if variceal hemorrhage is uncontrolled. As with terlipressin therapy should be continued for 2-5 days (Table 2).

Following initiation of vasoactive agents, EGD should be performed within 12 hours of presentation [10]. EVBL is superior to sclerotherapy and is the modality of choice [19]. The combination of EVBL with pharmacological therapy is the current standard of care and when compared to EVBL alone it improves initial control of bleeding and 5-day hemostasis without a mortality benefit [36]

\section{Role of TIPS in Acute Variceal Bleeding}

The use of transjugular intrahepatic portosystemic shunt (TIPS) in acute variceal hemorrhage has been historically reserved for salvage therapy in patients who have failed endoscopic and pharmacological treatment. However, a recent randomized controlled trial looking at early TIPS, defined as within 72 hours of standard therapy (EVBL + antibiotic + vasoactive agent), versus standard therapy alone showed that in patients with Child B/C cirrhosis the early use of TIPS was associated with a reduction in the failure to control bleeding, lower incidence of rebleeding, and decreased mortality rate [37]. In addition, the TIPS group did not have an increased incidence of hepatic encephalopathy. Notably, however, the outcomes in the nonearly TIPS group were unusually poor. Although more studies will be needed to confirm these findings, the early use of TIPS should be considered in patients with severe liver disease who present with acute variceal bleeding following initial standard therapy.

\section{Secondary Prevention}

Patients who survive an episode of acute variceal hemorrhage are at high risk of recurrence. Overall, $60 \%$ of these individuals will rebleed within 2 years with a mortality rate of $33 \%$ $[4,8]$. Therapy aimed at reducing this risk is essential and should be implemented as soon as the initial hemorrhage is controlled $[9,10]$. Multiple modes of treatment have been investigated including monotherapy with nonselective beta-blockers, combination medical therapy, EVBL with or without pharmacological adjunct, and TIPS.

Nonselective beta-blockers have been shown to decrease rebleeding rates from $60 \%$ to $42-43 \%$ likely secondary to the decrease in portal pressure $[4,8,24]$. Further portal pressure reduction can be achieved when they are combined with oral nitrates (ISMN) [38]. Nitrate-induced venodilation decreases cardiac output and blood pressure, which can lead to a baroreceptor-mediated splanchnic vasoconstriction and fall in portal pressure [39]. It may also have a direct vasodilatory effect on the portosystemic circulation; however, a randomized trial and a recent meta-analysis did not show any benefit in adding a nitrate. In addition, combined therapy is associated with more adverse effects leading to discontinuation of treatment $[40,41]$.

In terms of endoscopic therapy, EVBL is superior to sclerotherapy and is the method of choice $[42,43]$. Meta-analysis of several randomized controlled trials (719 patients) comparing EVBL versus combination medical therapy, with nonselective beta-blockers and nitrates, showed no difference in rebleeding rate and increased survival in the medically 
TABLE 2: Initial medical management of acute variceal bleeding.

\begin{tabular}{|c|c|c|c|}
\hline Treatment & Dose & Duration & Details \\
\hline \multicolumn{4}{|l|}{ Antibiotics } \\
\hline Ceftriaxone & 1 g IV daily & 5-7 days & $\begin{array}{l}\text { Severe cirrhosis Child B/C and/or high suspicion of } \\
\text { quinolone resistance }\end{array}$ \\
\hline Ciprofloxacin & $400 \mathrm{mg}$ IV or $500 \mathrm{mg}$ oral twice daily & 5-7 days & $\begin{array}{l}\text { Mild cirrhosis Child A and low suspicion of quinolone } \\
\text { resistance }\end{array}$ \\
\hline Norfloxacin & $400 \mathrm{mg}$ oral twice daily & 5-7days & $\begin{array}{l}\text { Mild cirrhosis Child A and low suspicion of quinolone } \\
\text { resistance }\end{array}$ \\
\hline \multicolumn{4}{|l|}{ Vasoconstrictors } \\
\hline Octreotide & $50 \mu \mathrm{g}$ IV bolus, then infusion at $50 \mu \mathrm{g} / \mathrm{hr}$ & $2-5$ days & $\begin{array}{l}\text { Initial bolus can be repeated in the first hour if bleed } \\
\text { not controlled }\end{array}$ \\
\hline Terlipressin & $\begin{array}{c}2 \mathrm{mg} \text { IV every } 4 \mathrm{hr} \times 48 \mathrm{hr} \text {, then } 1 \mathrm{mg} \text { IV } \\
\text { every } 4 \mathrm{hr}\end{array}$ & $2-5$ days & Not available in North America \\
\hline Somatostatin & $250 \mu \mathrm{g}$ IV bolus, then $250-500 \mu \mathrm{g} / \mathrm{hr}$ & $2-5$ days & Not available in North America \\
\hline
\end{tabular}

treated group [44-47]. Also, two prospective trials suggest that the combination of EVBL with medical therapy (nadolol) may be superior to EVBL alone [48, 49]. The use of EVBL and a nonselective beta-blocker is the current recommendation for secondary prophylaxis and should be instituted without delay following initial bleed [10]. However, a recent randomized controlled trial looking at combination therapy $(\mathrm{EVBL}+$ nadolol + nitrate $)$ versus medical therapy alone (nadolol + nitrate) found no difference in rebleeding rates, need for rescue therapy, or mortality while the combination therapy was associated with more adverse events [50]. More studies will be needed to confirm these findings but future guidelines may move towards medical therapy alone.

Finally, TIPS in secondary prophylaxis has been shown to lower rebleeding rates when compared to the aforementioned medical/endoscopic therapy [51-53]. However, no mortality benefit has been demonstrated with TIPS and its use is associated with higher costs and incidence of hepatic encephalopathy. Therefore, the use of TIPS in secondary prophylaxis is not recommended; however, its use may be considered following failure with conventional medical therapy [10]. This may change with the advent of polytetrafluoroethylene- (PTFE-) covered prostheses, which substantially improves TIPS patency.

In summary, EVL in combination with nonselective betablockers is the method of choice in preventing recurrent variceal bleeding. The addition of nitrates can theoretically potentiate the portal pressure drop; however, it has not been shown to decrease mortality or rebleeding rates and is associated with greater side effects. TIPS is not recommended for secondary prophylaxis and should only be considered following failure with usual medical therapy. It decreases rebleeding rates without a mortality benefit while being associated with higher costs and incidence of hepatic encephalopathy. Whether the new PTFE covered stent will improve TIPS efficacy in secondary prophylaxis remains to be seen, but for the moment its use is restricted to those cases where other therapies have failed.

\section{Conclusion}

The management of gastroesophageal varices has evolved over the last decade resulting in improved mortality and morbidity rates. Primary prevention with nonselective betablockers or EVBL should be initiated in all patients with medium to large varices and in patients with small varices associated with high risk features such as red wale marks and/or advanced cirrhosis. While prophylaxis in patients with small varices without high risk features is considered optional. In acute bleeding, vasoactive agents such as octreotide or terlipressin should be initiated along with antibiotics followed by EVBL within 12 hours of presentation. These patients are at increase risk for rebleeding and secondary prevention should be initiated immediately following control of initial hemorrhage with serial EVBL and nonselective beta-blocker. Currently, TIPS' role in secondary prophylaxis is limited except for failure with conventional therapy; however, this may change with the advent of PTFE covered stents. Although therapy for patients with varices has made significant progress, it will continue to improve with better endoscopic technique, novel pharmacological agents, greater efficiency of liver transplant, and more effective rescue therapy.

\section{References}

[1] Y. Iwakiri and R. J. Groszmann, "Vascular endothelial dysfunction in cirrhosis," Journal of Hepatology, vol. 46, no. 5, pp. 927934, 2007.

[2] R. J. Groszmann, G. Garcia-Tsao, J. Bosch et al., "Beta-blockers to prevent gastroesophageal varices in patients with cirrhosis," The New England Journal of Medicine, vol. 353, no. 21, pp. 2254-2261, 2005.

[3] M. Merli, G. Nicolini, S. Angeloni et al., "Incidence and natural history of small esophageal varices in cirrhotic patients," Journal of Hepatology, vol. 38, no. 3, pp. 266-272, 2003.

[4] G. D'Amico, L. Pagliaro, and J. Bosch, "Pharmacological treatment of portal hypertension: an evidence-based approach," Seminars in Liver Disease, vol. 19, no. 4, pp. 475-505, 1999. 
[5] J. G. Abraldes, C. Villanueva, R. Banares et al., "Hepatic venous pressure gradient and prognosis in patients with acute variceal bleeding treated with pharmacologic and endoscopic therapy," Journal of Hepatology, vol. 48, no. 2, pp. 229-236, 2008.

[6] J. Bosch, D. Thabut, A. Albillos et al., "Recombinant factor VIIa for variceal bleeding in patients with advanced cirrhosis: a randomized, controlled trial," Hepatology, vol. 47, no. 5, pp. 1604-1614, 2008.

[7] C. Villanueva, M. Piqueras, C. Aracil et al., "A randomized controlled trial comparing ligation and sclerotherapy as emergency endoscopic treatment added to somatostatin in acute variceal bleeding," Journal of Hepatology, vol. 45, no. 4, pp. 560-567, 2006.

[8] J. Bosch and J. C. Garcia-Pagan, "Prevention of variceal rebleeding," The Lancet, vol. 361, no. 9361, pp. 952-954, 2003.

[9] G. Garcia-Tsao and J. Bosch, "Management of varices and variceal hemorrhage in cirrhosis," The New England Journal of Medicine, vol. 362, pp. 823-832, 2010.

[10] G. Garcia-Tsao, A. J. Sanyal, N. D. Grace, and W. Carey, "Prevention and management of gastroesophageal varices and variceal hemorrhage in cirrhosis," Hepatology, vol. 46, no. 3, pp. 922-938, 2007.

[11] U. Thalheimer, C. Triantos, J. Goulis, and A. K. Burroughs, "Management of varices in cirrhosis," Expert Opinion on Pharmacotherapy, vol. 12, no. 5, pp. 721-735, 2011.

[12] J. Bosch, A. Berzigotti, J. C. Garcia-Pagan, and J. G. Abraldes, "The management of portal hypertension: rational basis, available treatments and future options," Journal of Hepatology, vol. 48, supplement 1, pp. S68-S92, 2008.

[13] J. Bosch, "Carvedilol for portal hypertension in patients with cirrhosis," Hepatology, vol. 51, no. 6, pp. 2214-2218, 2010.

[14] C. Merkel, R. Marin, P. Angeli et al., "A placebo-controlled clinical trial of nadolol in the prophylaxis of growth of small esophageal varices in cirrhosis," Gastroenterology, vol. 127, no. 2, pp. 476-484, 2004.

[15] L. L. Gluud, S. Klingenberg, D. Nikolova, and C. Gluud, "Banding ligation versus beta-blockers as primary prophylaxis in esophageal varices: systematic review of randomized trials," The American Journal of Gastroenterology, vol. 102, no. 12, pp. 2842-2848, 2007.

[16] C. S. Lay, Y. T. Tsai, F. Y. Lee et al., "Endoscopic variceal ligation versus propranolol in prophylaxis of first variceal bleeding in patients with cirrhosis," Journal of Gastroenterology and Hepatology, vol. 21, no. 2, pp. 413-419, 2006.

[17] J. G. Abraldes, I. Tarantino, J. Turnes, J. C. Garcia-Pagan, J. Rodes, and J. Bosch, "Hemodynamic response to pharmacological treatment of portal hypertension and long-term prognosis of cirrhosis," Hepatology, vol. 37, no. 4, pp. 902-908, 2003.

[18] R. M. Perez-Ayuso, J. M. Pique, J. Bosch et al., "Propranolol in prevention of recurrent bleeding from severe portal hypertensive gastropathy in cirrhosis," The Lancet, vol. 337, no. 8755, pp. 1431-1434, 1991.

[19] J. C. Garcia-Pagan and J. Bosch, "Endoscopic band ligation in the treatment of portal hypertension," Nature Clinical Practice Gastroenterology \& Hepatology, vol. 2, no. 11, pp. 526-535, 2005.

[20] S. K. Sarin, M. Wadhawan, S. R. Agarwal, P. Tyagi, and B. C. Sharma, "Endoscopic variceal ligation plus propranolol versus endoscopic variceal ligation alone in primary prophylaxis of variceal bleeding," The American Journal of Gastroenterology, vol. 100, no. 4, pp. 797-804, 2005.
[21] D. G. Koch, M. R. Arguedas, and M. B. Fallon, "Risk of aspiration pneumonia in suspected variceal hemorrhage: the value of prophylactic endotracheal intubation prior to endoscopy," Digestive Diseases and Sciences, vol. 52, no. 9, pp. 2225-2228, 2007.

[22] S. J. Rudolph, B. K. Landsverk, and M. L. Freeman, "Endotracheal intubation for airway protection during endoscopy for severe upper GI hemorrhage," Gastrointestinal Endoscopy, vol. 57, no. 1 , pp. 58-61, 2003.

[23] B. Castaneda, J. Morales, R. Lionetti et al., "Effects of blood volume restitution following a portal hypertensive-related bleeding in anesthetized cirrhotic rats," Hepatology, vol. 33, no. 4, pp. 821-825, 2001.

[24] R. de Franchis, "Evolving consensus in portal hypertension report of the Baveno IV consensus workshop on methodology of diagnosis and therapy in portal hypertension," Journal of Hepatology, vol. 43, no. 1, pp. 167-176, 2005.

[25] N. Hilzenrat, A. Arish, A. Yaari, Y. Almog, and E. Sikuler, "Blood viscosity, hemodynamics and vascular hindrance in a rat model of acute controlled bleeding and volume restitution with blood or Haemaccel," Acta Anaesthesiologica Scandinavica, vol. 45, no. 3, pp. 371-376, 2001.

[26] S. Vivas, M. Rodriguez, M. A. Palacio, A. Linares, J. L. Alonso, and L. Rodrigo, "Presence of bacterial infection in bleeding cirrhotic patients is independently associated with early mortality and failure to control bleeding," Digestive Diseases and Sciences, vol. 46, no. 12, pp. 2752-2757, 2001.

[27] B. Bernard, J. D. Grange, E. N. Khac, X. Amiot, P. Opolon, and T. Poynard, "Antibiotic prophylaxis for the prevention of bacterial infections in cirrhotic patients with gastrointestinal bleeding: a meta-analysis," Hepatology, vol. 29, no. 6, pp. 16551661, 1999.

[28] J. Fernandez, L. R. del Arbol, C. Gomez et al., "Norfloxacin vs ceftriaxone in the prophylaxis of infections in patients with advanced cirrhosis and hemorrhage," Gastroenterology, vol. 131, no. 4, pp. 1049-1056, 2006.

[29] J. Pohl, K. Pollmann, P. Sauer, A. Ring, W. Stremmel, and T. Schlenker, "Antibiotic prophylaxis after variceal hemorrhage reduces incidence of early rebleeding," Hepato-Gastroenterology, vol. 51, no. 56, pp. 541-546, 2004.

[30] K. Soares-Weiser, M. Brezis, R. Tur-Kaspa, and L. Leibovici, "Antibiotic prophylaxis for cirrhotic patients with gastrointestinal bleeding," Cochrane Database of Systematic Reviews, no. 2, Article ID CD002907, 2002.

[31] M. Bildozola, D. Kravetz, J. Argonz et al., "Efficacy of octreotide and sclerotherapy in the treatment of acute variceal bleeding in cirrhotic patients. A prospective, multicentric, and randomized clinical trial," Scandinavian Journal of Gastroenterology, vol. 35, no. 4, pp. 419-425, 2000.

[32] A. Escorsell, L. R. del Arbol, R. Planas et al., "Multicenter randomized controlled trial of terlipressin versus sclerotherapy in the treatment of acute variceal bleeding: the TEST study," Hepatology, vol. 32, no. 3, pp. 471-476, 2000.

[33] G. Ioannou, J. Doust, and D. C. Rockey, "Terlipressin for acute esophageal variceal hemorrhage," Cochrane Database of Systematic Reviews, no. 1, Article ID CD002147, 2003.

[34] R. de Franchis, "Somatostatin, somatostatin analogues and other vasoactive drugs in the treatment of bleeding oesophageal varices," Digestive and Liver Disease, vol. 36, supplement 1, pp. S93-S100, 2004.

[35] D. A. Corley, J. P. Cello, W. Adkisson, W. F. Ko, and K. Kerlikowske, "Octreotide for acute esophageal variceal bleeding: a meta-analysis," Gastroenterology, vol. 120, no. 4, pp. 946-954, 2001. 
[36] R. Banares, A. Albillos, D. Rincon et al., "Endoscopic treatment versus endoscopic plus pharmacologic treatment for acute variceal bleeding: a meta-analysis," Hepatology, vol. 35, no. 3, pp. 609-615, 2002.

[37] J. C. Garcia-Pagan, K. Caca, C. Bureau et al., "Early use of TIPS in patients with cirrhosis and variceal bleeding," The New England Journal of Medicine, vol. 362, no. 25, pp. 2370-2379, 2010.

[38] J. C. Garcia-Pagan, F. Feu, J. Bosch, and J. Rodes, "Propranolol compared with propranolol plus isosorbide-5-mononitrate for portal hypertension in cirrhosis. A randomized controlled study," Annals of Internal Medicine, vol. 114, no. 10, pp. 869873, 1991.

[39] A. T. Blei, D. Ganger, H. L. Fung, and R. Groszmann, “Organic nitrates in portal hypertension," European Heart Journal, vol. 9, pp. 205-211, 1988.

[40] L. L. Gluud, E. Langholz, and A. Krag, "Meta-analysis: isosorbide-mononitrate alone or with either beta-blockers or endoscopic therapy for the management of oesophageal varices," Alimentary Pharmacology \& Therapeutics, vol. 32, no. 7, pp. 859-871, 2010.

[41] J. Gournay, C. Masliah, T. Martin, D. Perrin, and J. P. Galmiche, "Isosorbide mononitrate and propranolol compared with propranolol alone for the prevention of variceal rebleeding," Hepatology, vol. 31, no. 6, pp. 1239-1245, 2000.

[42] R. de Franchis and M. Primignani, "Endoscopic treatments for portal hypertension," Seminars in Liver Disease, vol. 19, no. 4, pp. 439-455, 1999.

[43] L. Laine and D. Cook, "Endoscopic ligation compared with sclerotherapy for treatment of esophageal variceal bleeding. A meta-analysis," Annals of Internal Medicine, vol. 123, no. 4, pp. 280-287, 1995.

[44] G. H. Lo, W. C. Chen, C. K. Lin et al., "Improved survival in patients receiving medical therapy as compared with banding ligation for the prevention of esophageal variceal rebleeding," Hepatology, vol. 48, no. 2, pp. 580-587, 2008.

[45] D. Patch, C. A. Sabin, J. Goulis et al., "A randomized, controlled trial of medical therapy versus endoscopic ligation for the prevention of variceal rebleeding in patients with cirrhosis," Gastroenterology, vol. 123, no. 4, pp. 1013-1019, 2002.

[46] G. Romero, D. Kravetz, J. Argonz et al., "Comparative study between nadolol and 5-isosorbide mononitrate vs. endoscopic band ligation plus sclerotherapy in the prevention of variceal rebleeding in cirrhotic patients: a randomized controlled trial," Alimentary Pharmacology \& Therapeutics, vol. 24, no. 4, pp. 601-611, 2006.

[47] C. Villanueva, J. Minana, J. Ortiz et al., "Endoscopic ligation compared with combined treatment with nadolol and isosorbide mononitrate to prevent recurrent variceal bleeding," The New England Journal of Medicine, vol. 345, no. 9, pp. 647-655, 2001.

[48] J. de la Pena, E. Brullet, E. Sanchez-Hernandez et al., "Variceal ligation plus nadolol compared with ligation for prophylaxis of variceal rebleeding: a multicenter trial," Hepatology, vol. 41, no. 3, pp. 572-578, 2005.

[49] G. H. Lo, K. H. Lai, J. S. Cheng et al., "Endoscopic variceal ligation plus nadolol and sucralfate compared with ligation alone for the prevention of variceal rebleeding: a prospective, randomized trial," Hepatology, vol. 32, no. 3, pp. 461-465, 2000.

[50] C. Villanueva, C. Aracil, A. Colomo et al., "Clinical trial: a randomized controlled study on prevention of variceal rebleeding comparing nadolol + ligation vs. hepatic venous pressure gradient-guided pharmacological therapy," Alimentary Pharmacology \& Therapeutics, vol. 29, no. 4, pp. 397-408, 2009.

[51] V. Gulberg, M. Schepke, G. Geigenberger et al., “Transjugular intrahepatic portosystemic shunting is not superior to endoscopic variceal band ligation for prevention of variceal rebleeding in cirrhotic patients: a randomized, controlled trial," Scandinavian Journal of Gastroenterology, vol. 37, no. 3, pp. 338-343, 2002.

[52] R. Jalan, E. H. Forrest, A. J. Stanley et al., "A randomized trial comparing transjugular intrahepatic portosystemic stentshunt with variceal band ligation in the prevention of rebleeding from esophageal varices," Hepatology, vol. 26, no. 5, pp. 1115-1122, 1997.

[53] G. Pomier-Layrargues, J. P. Villeneuve, M. Deschenes et al., "Transjugular intrahepatic portosystemic shunt (TIPS) versus endoscopic variceal ligation in the prevention of variceal rebleeding in patients with cirrhosis: a randomised trial," Gut, vol. 48, no. 3, pp. 390-396, 2001. 


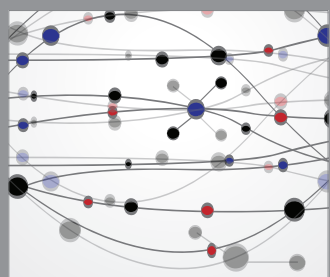

The Scientific World Journal
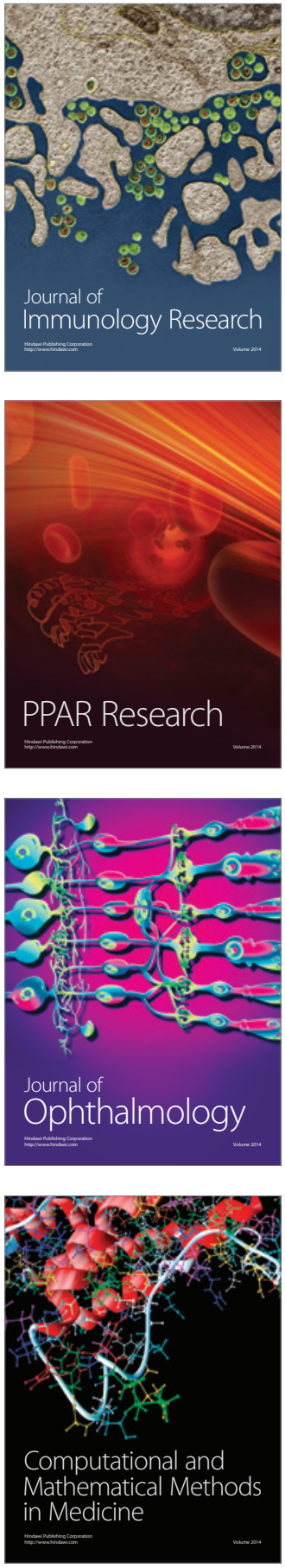

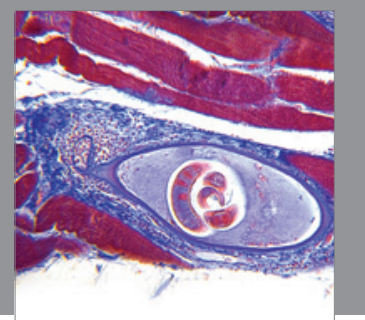

Gastroenterology

Research and Practice
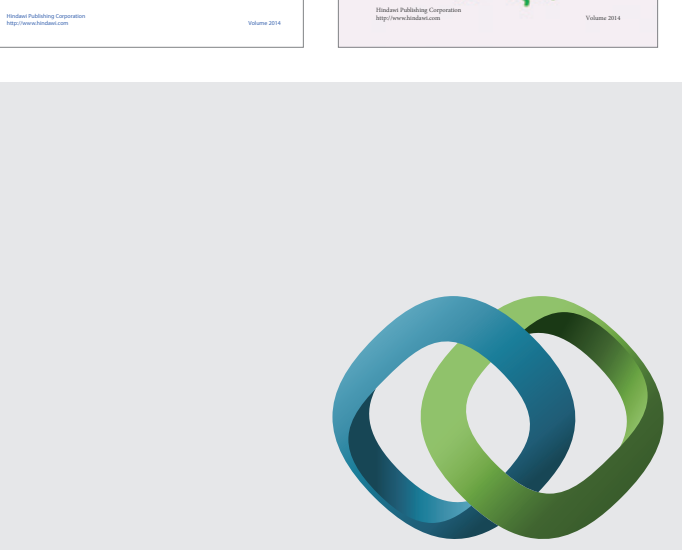

\section{Hindawi}

Submit your manuscripts at

http://www.hindawi.com
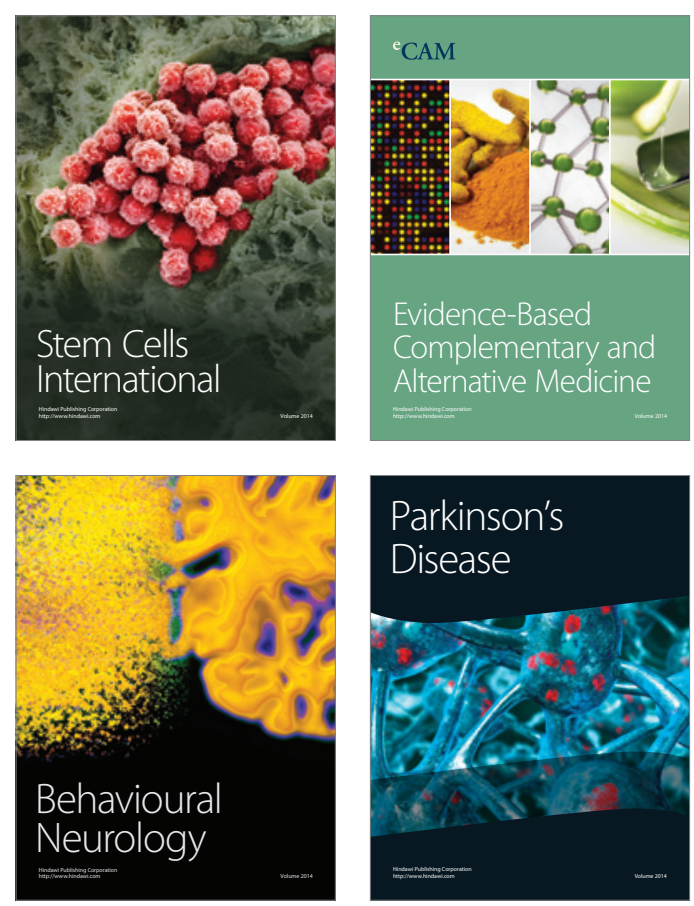

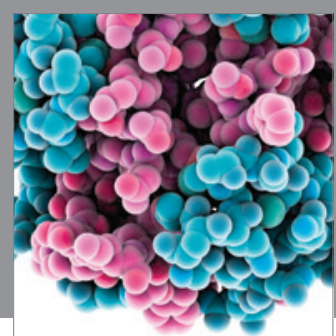

Journal of
Diabetes Research

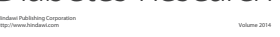

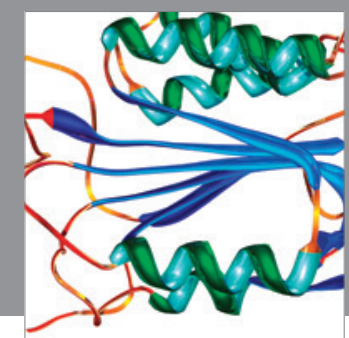

Disease Markers
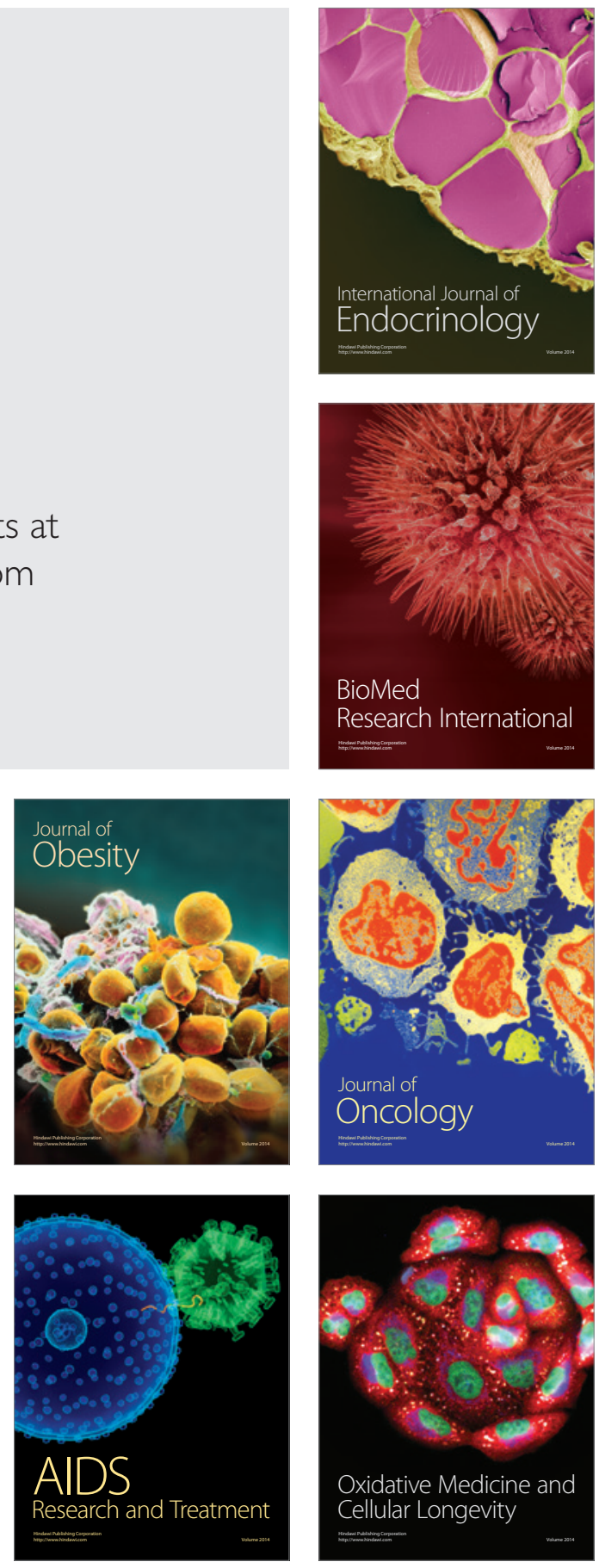